\title{
Hypoglycemic and High Dosage Effects of Bidens pillosa in Type-1 Diabetes Mellitus
}

\author{
Mulkah 0. Ajagun-Ogunleye1,2*, Michael Tirwomwe1, Ruth Nyaboke Mitaki, \\ John Nnamdi Ejekwumadu1, Keneth Iceland Kasozi ${ }^{3}$, Julia Pantoglou, \\ Elvis Ngala Mbiydzenyuy ${ }^{3}$, Nancy Bonareri Mitaki1 \\ ${ }^{1}$ Department of Biochemistry, Faculty of Biomedical Sciences, Kampala International University Western \\ Campus, Bushenyi, Uganda \\ ${ }^{2}$ Institute of Biomedical Research, Kampala International University Western Campus, Bushenyi, Uganda \\ ${ }^{3}$ Department of Physiology, Faculty of Biomedical Sciences, Kampala International University Western Campus, \\ Bushenyi, Uganda \\ ${ }^{4}$ Institute of Tropical Medicine and International Health, Charité-Universitätsmedizin Berlin, Berlin, Germany \\ Email: ${ }^{*}$ mulka4real@yahoo.com, ${ }^{*}$ kicelandy@gmail.com
}

Received 4 May 2015; accepted 7 July 2015; published 10 July 2015

Copyright (C) 2015 by authors and Scientific Research Publishing Inc.

This work is licensed under the Creative Commons Attribution International License (CC BY).

http://creativecommons.org/licenses/by/4.0/

(c) (7) Open Access

\section{Abstract}

Ethno-pharmaceutical products have received a lot of international attention in the scientific community in the management of diabetes mellitus (DM). In this study we determined the anti-diabetic and high dosage effects of Bidens pliosa in type 1 DM (T1DM). Methodology: Thirty rats were divided into six groups and subgrouped into the extract and non extract treatment groups. The extract treated group was subdivided into three groups which received $200 \mathrm{mg} / \mathrm{kg}, 400 \mathrm{mg} / \mathrm{kg}$ and $800 \mathrm{mg} / \mathrm{kg}$ dosage treatments respectively. The blood glucose levels were monitored using a standard glucometer for one month, and biochemical analysis of the two liver function enzymes; Alanine aminotransferase (ALT) and Aspartate aminotransferase (AST) were carried out at the Institute of Biomedical Research (IBR-KIU-WC) at the end of week IV. The study revealed that Bidens pilosa maintained hypoglycemia for a period of two weeks and this status was lost in subsequent weeks. T1DM rats treated with a dosage of $200 \mathrm{mg} / \mathrm{kg}$ showed a better recovery (355.25 - 164.5 $\mathrm{mg} / \mathrm{dl}$ ) of the glucose levels, followed by those that were being treated at $400 \mathrm{mg} / \mathrm{kg}$. The AST and ALT enzymes in blood varied with a mean \pm SEM $(33.72 \pm 32.32$ to $-7.23 \pm 12.61$ IU and $22.98 \pm$ 11.12 to $42 \pm 38.2 \mathrm{IU}$, respectively) in both the glibencimide ${ }^{\circledR}$ and in the $800 \mathrm{mg} / \mathrm{kg}$ treatment groups in the study. High dosages of extract were associated $(P=0.049)$ with increased systemic enzyme leakage. In conclusion, tissue degeneration caused by high levels of the extract was accompanied by leakage of various enzymes (AST and ALT) into the blood, which could be a major etiological factor for the development of secondary systemic pathologies, thus potentially worsening the effects of an existing T1DM prognosis in human patients. The preliminary results indi-

\footnotetext{
${ }^{*}$ Corresponding authors.
}

How to cite this paper: Ajagun-Ogunleye, M.O., Tirwomwe, M., Mitaki, R.N., Ejekwumadu, J.N., Kasozi, K.I., Pantoglou, J., Mbiydzenyuy, E.N. and Mitaki, N.B. (2015) Hypoglycemic and High Dosage Effects of Bidens pilosa in Type-1 Diabetes Mellitus. Journal of Diabetes Mellitus, 5, 146-154. http://dx.doi.org/10.4236/jdm.2015.53018 
cate that a dose of Bidens pilosa has an anti-diabetic effect for a limited initial duration before starting to cause systemic toxicological effects. It is highly recommended that further investigation into the cellular mechanisms and consequences of any therapy involving Bidens pilosa be carried out.

\section{Keywords}

\section{Type 1 Diabetes Mellitus, Bidens pilosa and Diabetes, Ethno-Pharmaceutical Medicine in Uganda, Sub-Saharan Africa and Diabetes}

\section{Introduction}

Global prevalence of diabetes mellitus (DM) is estimated to be over $10 \%$ especially with increasing disease incidence from Sub-Saharan Africa coupled with its low case reporting [1] [2]. The prevalence of DM in association with other metabolic diseases has been reported in Uganda [3] [4]. Gestational diabetes has been reported amongst Sub-Saharan mothers and it has been shown that this can lead to developmental challenges amongst infants [5]. Recent studies in the region have associated the disease in newborns with genetic transmission as a result of the risk possessed by family members in the communities [6]. Risk factors have been shown to exist ranging from lifestyle patterns to nutritional discipline [4] [7]. This has led to the development of herbal management therapies within the communities of Sub-Saharan Africa since clinical treatment therapies are asymptomatic [8] [9]. Bidens pliosa is an American native medicinal plant that is widely distributed across the African continent [10] [11]. The development of the herbal industry in tropical Africa has led to the innovation of various therapies for the management of medical cases, whose treatment and management are asymptomatic as well [12] [13]. These herbal therapies often have unfounded mechanism of action, and probably play a crucial role in the development of adverse drug reactions and treatment failure [11] [14].

Analyses of selected enzyme activities in blood serum give valuable diagnostic information for a number of metabolic disease conditions [15]. Alanine aminotransferase (ALT) and aspartate aminotransferase (AST) are important in the diagnosis of organ (esp. of heart and liver) damage caused by heart attack, drug toxicity, or infection due to the leakage of a variety of enzymes, including these aminotransferases, which leak from the damaged liver or heart cells [16]. ALT catalyzes the transfer of the amino group of alanine to $\alpha$-ketoglutarate, resulting in the formation of pyruvate and glutamate, and the reaction is readily reversible. However, during amino acid catabolism, this enzyme (like most aminotransferases) functions in the direction of glutamate synthesis. Thus, glutamate, in effect, acts as a "receiver" of nitrogen from alanine. AST is an exception to the rule that aminotransferases "channel" amino groups to form glutamate. During amino acid catabolism, AST transfers amino groups from glutamate to oxaloacetate, forming aspartate, which is used as a source of nitrogen in the urea cycle and the reaction is also reversible. This study was conducted to determine the effects of Bidens pilosa on hyperglycemia and liver enzymes (AST and ALT) as biological markers for the pathological effects of the extract in Wister rats with type $1 \mathrm{DM}$ (T1DM).

\section{Materials and Methods}

\subsection{Study Design}

The study involved thirty adult Wister rats (Norwegian rattus) that were divided into six groups and monitored for a period of 10 weeks at the Department of Biochemistry and Institute of Biomedical Research (IBR), Kampala International University, Ishaka, Bushenyi, Uganda.

\subsection{Plant Collection and Extraction}

The leaves were processed using standard protocols [11]. Briefly; fresh plant leaves were collected from Bwegiragye village in Ishaka Bushenyi which is within the university community. The leaves were dried under a shade in the laboratory for 14 days. These were pulverized using an electric blender, and the powdered material 
extracted using distilled water on a mechanical shaker (Stuart Scientific Orbital Shaker, UK) for 48 hours. 200 gms of powder were weighed and dissolved in $500 \mathrm{mls}$ of distilled water, and stirred using a stirring rod. The mixture was poured in a 1 litre Beaker and mixed thoroughly on an electric shaker for 48 hours. Mixture was sieved with a clean cloth and filtered using a Watman filter paper (125 mm diameter). Filtrate was kept in a 1000 mlplastic beaker and the weight of the filtrate $(380 \mathrm{gm})$ was weighed, and then concentrated in the oven at about $28^{\circ} \mathrm{C}-30^{\circ} \mathrm{C}$ for two weeks. The beaker containing the extract was weighed which gave about $25 \mathrm{gm}$ of extract.

\subsection{Acute Toxicity Test}

Experimental animals were weighed and divided into three groups, 5 animals in each group, animals were weighed and the calculation of volume of extract to be administered to each animal was based on body weight and size. Doses were in the range of low, medium and high; $200 \mathrm{mg} / \mathrm{kg}, 800 \mathrm{mg} / \mathrm{kg}, 1000 \mathrm{mg} / \mathrm{kg}$ and $2000 \mathrm{mg} /$ $\mathrm{kg}$. Animals were then placed in cages and observed for signs of acute toxicity. The $\mathrm{LD}_{50}$ was established at $1000 \mathrm{mg} / \mathrm{kg}$ and this was used as foundation for the study dosage groupings and signs observed were basically body shaking which progressed to severe tremors and subsequent death.

\subsection{Diabetes Induction}

Diabetes was induced by injecting $200 \mathrm{mg} / \mathrm{kg}$ of alloxan monohydrate intraperitoneally to overnight-fasted rats (the $\mathrm{LD}_{50}$ was determined by an initial induction of the condition until successful results were obtained). $10 \%$ glucose solution bottles were kept in the cages for the next $24 \mathrm{~h}$ to prevent hypoglycemia. After $72 \mathrm{~h}$ of injection, fasting blood glucose (FBG) levels were measured. Animals which develop more than $200 \mathrm{mg} / \mathrm{dl}$ glucose levels were used for the study.

\subsection{Study Groups}

Experimental animals were divided into six groups each consisting of a minimum of five adult male rats $(\mathrm{n}=5)$ aged 4 months. Grouping was made according to concentration of extract for treatment. These included: $200 \mathrm{mg}$, $400 \mathrm{mg}, 800 \mathrm{mg}$ extract groups as well as controls which included normal saline group, Glibenclamide ${ }^{\mathbb{B}}(0.5$ $\mathrm{mg} / \mathrm{kg}$ ) group and the sixth group consisting of normal non diabetic rats.Treatments were continued orally for 4 weeks. At the end of the 4 th week the rats were fasted for $16 \mathrm{~h}$ and blood liver enzymes were determined. Blood was collected and biochemical markers measured. The blood glucose levels were measured using Accu-Chek Active ${ }^{\mathrm{TM}}$ Test Meter on blood from the rat's lateral tail vein. The plasma profile of blood was determined from blood collected from retro-orbital venous plexus of the rats under low dosage of ether anesthesia using capillary tubes into Eppendorf tubes containing heparin. The plasma was then separated by centrifugation ( $5 \mathrm{~min}, 5000$ $\mathrm{rpm}$ ) and analyzed for specific liver function enzymes AST and ALT using commercial kits and Spectrophotemetericanalysison the fourth week after induction of T1DM. Weights of tissues were taken after one month of administering the extract, using amettle AE260 Delta Range electronic weighing balance.

\subsection{Data Analysis}

Data was expressed as means from the samples analyzed. The means of fasting blood glucose (FBG) levels for the test and control groups were compared at different times by one-way Analysis of Variance (One-Way ANOVA) using SPSS 16 software. Linear regression was carried out to determine treatment associations and a $p$ value $<0.05$ was considered statistically significant.

\subsection{Ethical Consideration}

No ethical approval was required since the study involved only animal research models. All animals were handled and treated in accordance to the International ethical guidelines on the Care and Management of Laboratory Animals (IUAC).

\section{Results}

Upon injection with alloxan, hyperglycemia confirmed diabetic model as shown in week 0 of Table 1 . Hypoglycemia occurred within the first two weeks following treatment with the extract and greatest effect was higher 
with increasing dose of the extract. There was an increase in the fasting blood glucose with normal saline above $280 \mathrm{mg} / \mathrm{dl}$ of blood for the four weeks of the study. T1DM rats that were being treated with an extract at 200 $\mathrm{mg} / \mathrm{kg}$ showed a better recovery ( $355.25-164.5 \mathrm{mg} / \mathrm{dl}$ of blood) of the blood glucose levels, followed by those that were being treated at $400 \mathrm{mg} / \mathrm{kg}$ than those which received normal saline and $800 \mathrm{mg} / \mathrm{kg}(334-175.75$ $\mathrm{mg} / \mathrm{dl}$ of blood) as shown in Table 1 .

Statistical analysis showed that there existed no relationship between the different dosages administered within the first three weeks $(\mathrm{P}>0.05)$ on the blood glucose levels. Further analysis of the variance during week I and II showed no statistical significance $(\mathrm{P}=0.637)$ on the blood glucose levels as shown below. Further analysis of glycemic effects between week I and III showed that the $800 \mathrm{mg} / \mathrm{kg}$ treatment group had significant results as shown in Figure 1.

The rats that were being treated with lower dosage $(200 \mathrm{mg} / \mathrm{kg})$ showed the highest rate of adaptability than those that were being treated with higher dosage and normal saline which showed the least adaptation to recovery. By the fourth week, the majority of the rats had died as shown in Table 2. Analysis of Variance (ANOVA) showed that there was no statistical significance in the glucose concentrations in the different groups $(\mathrm{P}=0.44)$.

Further analysis of the glycemic effects showed that the $800 \mathrm{mg} / \mathrm{kg}$ extract had significant hypoglycemic effects slightly comparable to those from the Glibenclamide ${ }^{\circledR}$. The effects of the extracts $(200 \mathrm{mg} / \mathrm{kg}, 400 \mathrm{mg} / \mathrm{kg}$, and $800 \mathrm{mg} / \mathrm{kg}$ ) and normal saline on serum AST were measured at week IV. This was shown to be considerably lower at decreased dosage of the extract as shown in Table 3 and Table 4.

Table 1. Mean glycemic changes after administration of extract over four weeks.

\begin{tabular}{|c|c|c|c|c|c|}
\hline \multirow{2}{*}{ Dosage/Time } & \multicolumn{5}{|c|}{ Time in Weeks } \\
\hline & 0 & I & II & III & IV \\
\hline $200 \mathrm{mg} / \mathrm{kg}$ & 355.3 & 275.25 & 164.5 & 257.3 & 271.7 \\
\hline $400 \mathrm{mg} / \mathrm{kg}$ & 348.3 & 284 & 238.8 & 283.8 & $0^{*}$ \\
\hline $800 \mathrm{mg} / \mathrm{kg}$ & 334 & 240 & 175.75 & 298.8 & $0^{*}$ \\
\hline $\mathrm{Glb} 0.5 \mathrm{mg} / \mathrm{kg}$ & 288.8 & 77.2 & 201.5 & 72.4 & $0^{*}$ \\
\hline Normal saline & 375.3 & 153.3 & 335 & 395.7 & $0^{*}$ \\
\hline Non-diabetic & 73 & 59.6 & 73.2 & 81.6 & $0^{*}$ \\
\hline
\end{tabular}

Key: Glb $=$ Glibenclamide $\mathbb{R} ; 0^{*}=$ Time of death of rats.

Table 2. Showing analysis of variance between weeks I \& II.

\begin{tabular}{cccccc}
\hline Model & Sum of Squares & df & Mean Square & F & Sig. \\
Regression & 3020.69 & 1 & 3020.69 & 0.260 & 0.64 \\
Residual & 46388.64 & 4 & 11597.16 & & \\
\hline
\end{tabular}

Key: Sig. = significance; $\mathrm{df}=$ degrees of freedom.

Table 3. Showing AST (IU) in blood from the various rats under varying treatments.

\begin{tabular}{cccccc}
\hline \multirow{2}{*}{ Group } & \multicolumn{3}{c}{ Dosage/Treatment } \\
\cline { 2 - 5 } & Glb & $200 \mathrm{mg} / \mathrm{kg}$ & $400 \mathrm{mg} / \mathrm{kg}$ & $800 \mathrm{mg} / \mathrm{kg}$ & -51.33 \\
\hline 1 & 7.58 & 22.17 & 300.42 & -16.92 & 11.08 \\
2 & -8.17 & -12.83 & 2.33 & 17.50 & 10.50 \\
3 & 11.67 & 131.83 & 0.00 & 14.58 & 0 \\
4 & -4.67 & 0.00 & -2.33 & 0.00 & 0 \\
\hline
\end{tabular}


The levels of the AST enzyme were shown to be in the mean of $33.72 \pm 32.32 ;-7.23 \pm 12.61 ; 2.22 \pm 2.22$ in the Glibenclamide ${ }^{\circledR}, 800 \mathrm{mg} / \mathrm{kg}$ and normal saline treatment diabetic groups. Subsequent analysis of the serum for the ALT levels revealed that the levels of ALT were in the mean of 22.98 $\pm 11.12 ; 42 \pm 38.2 ; 199 \pm 189 \mathrm{IU}$ of blood for Glibenclamide ${ }^{\circledR}, 800 \mathrm{mg} / \mathrm{kg}$ and normal saline treatment groups respectively. Linear regression of the extracts from the $400 \mathrm{mg} / \mathrm{kg}$ and $800 \mathrm{mg} / \mathrm{kg}$ treatments were found to be associated $(P=0.049)$ with high liver AST as shown in Table 4.

The effect of increasing dosage of the extract in the diabetic rats was found not to be significant in relation to the Glibenclamide ${ }^{\circledR}(P=0.24)$, though a significant effect was shown in relation to the group treated with normal saline on the levels of AST and ALT in the study.

Further analysis revealed that there was no association between the treatment options and the levels of ALT as shown in Table 5.

\section{Discussion}

The study revealed that Bidens pilosa maintained hypoglycemia for a period of two weeks, and this status was lost in the subsequent period as shown in Table 1. The initial rise in FBG seems to offset the early anti-hyperglycemic effect of the crude extract which is in agreement with previous studies [12]. During the week I and week III, T1DM under the $800 \mathrm{mg} / \mathrm{kg}$ group showed the greatest therapeutical effect as the blood glucose levels were shown to be closer to the normal as shown in Figure 1. There was no statistical significance $(P=0.637)$ in the hypoglycemic effects towards the end of the study due to the loss of the efficacy of the extract probably as a result of onset of systemic injury, thus cancelling the positive effects observed earlier. This would probably be due to the accumulation of reactive oxygen species due to the oxidative properties of alloxan or the extract. This was followed by an increase in the liver enzymes AST and ALT and subsequent death as described in Table 3 and Table 4. High dosages of the extract were shown to be associated $(\mathrm{P}=0.049)$ with increased systemic damage. The findings in this study agree with previous findings that Bidens pilosa mode of action involves modulation of the immune system in rats as it protects the $\beta$-cells from the body antibodies [17]. The study revealed that marked toxicities in rats exist that were treated with the extract at high dosage $(>200 \mathrm{mg} / \mathrm{kg})$ which is in agreement with previous studies, despite the limited systemic toxicological analysis [18]. These finding are supported by a current study in which the toxicological effects of Bidens pilosa have been highlighted [11].

The liver enzymes AST and ALT that where measured in the study are primarily crucial for the indication of the level of systemic damage and as shown they increased with increasing dosage of extract in the different study groups. This could be due to increased systemic overload amidst a pre-existing autoimmune challenge thus accelerating systemic failure and death [19] [20]. Systemic degeneration (especially of the liver) caused by high dosage of the extract was accompanied by leakage of various enzymes from injured tissues into the blood,

Table 4. Showing ALT from the various rats under varying treatments.

\begin{tabular}{cccccc}
\hline \multirow{2}{*}{ Group } & \multicolumn{3}{c}{ Dosage/Treatment } \\
\cline { 2 - 6 } & Glb & $200 \mathrm{mg}$ & $400 \mathrm{mg}$ & $800 \mathrm{mg}$ & Normal saline \\
\hline 1 & 20.42 & -5.25 & 9.33 & 9.33 & 819.58 \\
2 & -7.58 & -8.17 & -11.08 & 12.25 & 449.17 \\
3 & 61.83 & -7.00 & -8.75 & -5.83 & -196.58 \\
4 & 18.08 & 0 & -35.58 & 194.25 & -35.00 \\
5 & 22.17 & 0 & 0 & 0 & -37.92 \\
\hline
\end{tabular}

Table 5. Showing Analysis of Variance (ANOVA) between weeks I \& II.

\begin{tabular}{ccccc}
\hline Model & Sum of Squares & df & Mean Square & Sig. \\
Regression & 208.67 & 3 & 69.56 & 0.031 \\
Residual & 2265.79 & 1 & 2265.79 \\
\hline
\end{tabular}




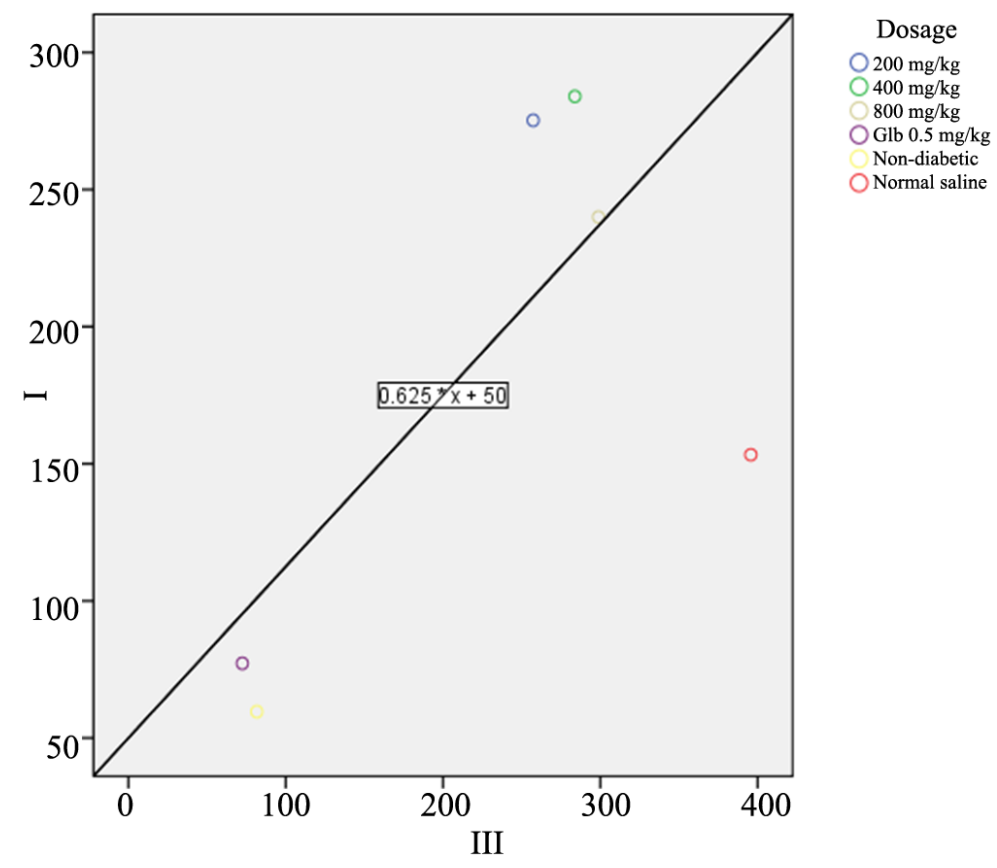

Figure 1. Showing changes in plasma glucose levels under different treatments for the period of week I and III.

which has been shown to be associated with development of secondary systemic pathologies [19]. In human patients, concurrent T1DM followed by generalized systemic challenges would make diagnosis of the disease more difficult as a result of the development of systemic failure probably due to high dosage of the extract. The toxicological effects have been shown to be due to increased plasma levels of enzymes (AST/ALT) due to liver injury in conjunction with other tissues leading to poor and delayed cellular recovery from injury. This probably is responsible for the increased mortalities exhibited in the study after week II, which is in agreement with recent findings [21].

Despite its use as an ingredient in food for human consumption, studies on systemic toxicity of Bidens pilosa in humans and animals are still inadequate and insufficient [10] [22]. This study evaluated the therapeutical and toxicological effects of Bidens pilosa, which showed that development of sub-chronic toxicities is a major challenge worth to be investigated further for the promotion of alternative medicine especially for Sub-Saharan Africa. Limitations to this study included limited organ systemic toxicological analysis as well as the limited biological markers measured for cellular injury due to severe financial constraints.

\section{Conclusion and Recommendations}

This study shows that Bidens pilosa has hypoglycemic effects on diabetes, but the toxicological effects associated with this plant, which occurs naturally within Sub-Saharan Africa including Uganda, are a major concern following high doses of the extract as shown in the study. The findings highlight the need for further toxicological studies regarding most of the herbal therapies in the region for improved development of community livelihoods and above all, for the protection of the general public against unnecessary development of drug reactions and resistance. The continuous usage of herbal therapies in rural communities of Sub-Saharan Africa should be used with caution and not indiscriminately as it has been throughout the ages.

\section{Acknowledgements}

The authors would like to extend their appreciation to the guidance and support that was offered by The Scientific Research Community of Kampala International University Western Campus. The work was carried out as part of thecurrent research group: "Non communicable diseases, Neurobiochemistry and Medicinal Plants(NNeM)", under the Department of Medical Biochemsity, Kampala International University Western Campus. 


\section{Competing Interests}

The authors declare there are no conflicting interests associated with this work.

\section{Authors Contributions}

All authors contributed equally, reviewed and approved the final manuscript.

M.O.A., N.M., M.T., N.E.: Designed the study, wrote the protocol and participated in data collection.

M.O.A., E.N., J.P., K.I.K.: Carried out literature search, analysis, writing and manuscript preparation.

\section{References}

[1] Shaw, J.E., Sicree, R.A. and Zimmet, P.Z. (2010) Global Estimates of the Prevalence of Diabetes for 2010 and 2030. Diabetes Research and Clinical Practice, 87, 4-14. http://dx.doi.org/10.1016/j.diabres.2009.10.007

[2] Namusisi, O., Sekandi, J.N., Kasasa, S., Wasswa, P., Kamara, N.T., Medard, B. and Mukanga, D. (2011) Project among Diabetes Patients at a Referral Hospital Clinic. Pan African Medical Journal, 8688, 1-11.

[3] Baalwa, J., Byarugaba, B.B., Kabagambe, E.K., Kabagambe, K.E. and Otim, A.M. (2010) Prevalence of Overweight and Obesity in Young Adults in Uganda. African Health Sciences, 10, 367-373.

http://www.pubmedcentral.nih.gov/articlerender.fcgi?artid=3052810\&tool=pmcentrez\&rendertype=abstract

[4] Mondo, C.K., Otim, M.A., Akol, G., Musoke, R. and Orem, J. (2013) The Prevalence and Distribution of Non-Communicable Diseases and Their Risk Factors in Kasese District, Uganda. Cardiovascular Journal of Africa, 24, 52-57. http://dx.doi.org/10.5830/CVJA-2012-081

[5] Odar, E., Wandabwa, J. and Kiondo, P. (2004) Maternal and Fetal Outcome of Gestational Diabetes Mellitus in Mulago Hospital, Uganda. African Health Sciences, 4, 9-14. http://www.pubmedcentral.nih.gov/articlerender.fcgi?artid=2141655\&tool=pmcentrez\&rendertype=abstract

[6] Naylor, R.N., Greeley, S.A.W., Bell, G.I. and Philipson, L.H. (2011) Genetics and Pathophysiology of Neonatal Diabetes Mellitus. Journal of Diabetes Investigation, 2, 158-169. http://dx.doi.org/10.1111/j.2040-1124.2011.00106.x

[7] Nyanzi, R., Wamala, R. and Atuhaire, L.K. (2014) Diabetes and Quality of Life : A Ugandan Perspective. Journal of Diabetes Research, 2014, 1-10. http://dx.doi.org/10.1155/2014/402012

[8] Hjelm, K. and Atwine, F. (2011) Health-Care Seeking Behaviour among Persons with Diabetes in Uganda : An Interview Study. BMC International Health and Human Rights, 11, 11. http://dx.doi.org/10.1186/1472-698X-11-11

[9] Tabuti, J.R.S., Kukunda, C.B., Kaweesi, D. and Kasilo, O.M.J. (2012) Herbal Medicine Use in the Districts of Nakapiripirit, Pallisa, Kanungu, and Mukono in Uganda. Journal of Ethnobiology and Ethnomedicine, 8, 1-15. http://dx.doi.org/10.1186/1746-4269-8-35

[10] Trojan-Rodrigues, M., Alves, T.L.S., Soares, G.L.G. and Ritter, M.R. (2012) Plants Used as Antidiabetics in Popular Medicine in Rio Grande do Sul, Southern Brazil. Journal of Ethnopharmacology, 139, 155-163. http://dx.doi.org/10.1016/j.jep.2011.10.034

[11] Yang, W.C. (2014) Botanical, Pharmacological, Phytochemical, and Toxicological Aspects of the Antidiabetic Plant Bidens pilosa L. Evidence-Based Complementary and Alternative Medicine, 2014, Article ID: 698617.

[12] Lans, C.A. (2006) Ethnomedicines Used in Trinidad and Tobago for Urinary Problems and Diabetes Mellitus. Journal of Ethnobiology and Ethnomedicine, 2, 45.

[13] Pan, S.Y., Zhou, S.F., Gao, S.H., Yu, Z.L., Zhang, S.F., Tang, M.K., et al. (2013) New Perspectives on How to Discover Drugs from Herbal Medicines: CAM's Outstanding Contribution to Modern Therapeutics. Evidence-Based Complementary and Alternative Medicine, 2013, Article ID: 627375. http://dx.doi.org/10.1155/2013/627375

[14] Ekor, M. (2014) The Growing Use of Herbal Medicines: Issues Relating to Adverse Reactions and Challenges in Monitoring Safety. Frontiers in Pharmacology, 4, 1-10. http://dx.doi.org/10.3389/fphar.2013.00177

[15] Pachikian, B.D., Neyrinck, A.M., Cani, P.D., Portois, L., Deldicque, L., De, F.C. and Delzenne, N.M. (2008) Alterations Related to Tissue Fatty Acid Composition. BMC Physiology, 11, 1-11.

[16] Ugarte, M., Brown, M., Hollywood, K.A., Cooper, G.J., Bishop, P.N. and Dunn, W.B. (2012) Metabolomic Analysis of Rat Serum in Streptozotocin-Induced Diabetes and after Treatment with Oral Triethylenetetramine (TETA). Genome Medicine, 4, 35. http://genomemedicine.com/content/4/4/AA http://dx.doi.org/10.1186/gm334

[17] Bartolome, A.P., Villaseñor, I.M. and Yang, W. (2013) Bidens pilosa L. (Asteraceae): Botanical Properties, Traditional Uses, Phytochemistry, and Pharmacology. Evidence-Based Complementary and Alternative Medicine, 2013, 1-51. http://dx.doi.org/10.1155/2013/340215 
[18] Trojan-Rodrigues, M., Alves, T.L.S., Soares, G.L.G. and Ritter, M.R. (2012) Plants Used as Antidiabetics in Popular Medicine in Rio Grande do Sul, Southern Brazil. Journal of Ethnopharmacology, 139, 155-163. http://dx.doi.org/10.1016/j.jep.2011.10.034

[19] Yang, W., Va, P., Bray, F., Gao, S., Gao, J. and Li, H. (2011) The Role of Pre-Existing Diabetes Mellitus on Hepatocellular Carcinoma Occurrence and Prognosis : A Meta-Analysis of Prospective Cohort Studies. PloS ONE, 6, 1-11. http://dx.doi.org/10.1371/journal.pone.0027326

[20] Petrak, F., Herpertz, S., Albus, C., Hermanns, N., Hiemke, C., Hiller, W., et al. (2013) Study Protocol of the Diabetes and Depression Study (DAD): A Multi-Center Randomized Controlled Trial to Compare the Efficacy of a DiabetesSpecific Cognitive Behavioral Group Therapy versus Sertraline in Patients with Major Depression and Poorly Controlled Diabetes Mellitus. BMC Psychiatry, 13, 206. http://dx.doi.org/10.1186/1471-244x-13-206

[21] Zhang, H., Gao, C., Fang, L. and Yao, S. (2013) Increased International Normalized Ratio Level in Hepatocellular Carcinoma Patients with Diabetes Mellitus. World Journal of Gastroenterology, 19, 2395-2403. http://dx.doi.org/10.3748/wjg.v19.i15.2395

[22] Yang, W. (2014) Aspects of the Antidiabetic Plant Bidens pilosa L. Evidence-Based Complementary and Alternative Medicine, 2014, 1-14. 
Ajagun-Ogunleye et al.

Abbreviations and Their Meanings

$\begin{array}{ll}\text { ALT } & \text { Alanine aminotransferase } \\ \text { AST } & \text { Aspartate aminotransferase } \\ \text { FBG } & \text { Fasting blood glucose } \\ \text { Glb } & \text { Glibenclamide } \\ \text { IBR } & \text { Institute of Biomedical Research } \\ \text { IU } & \text { International units } \\ \text { KIU-WC } & \text { Kampala International University Western Campus } \\ \text { LD }_{50} & \text { Lethal dose } \\ \text { SEM } & \text { Square error mean }\end{array}$

